\title{
FISH-based sperm aneuploidy screening in male partner of women with a history of recurrent pregnancy loss
}

\author{
Marjan Pourfahraji Fakhrabadi ${ }^{1,2}$, Seyed Mahdi Kalantar ${ }^{3}$, Fatemeh Montazeri ${ }^{1 *}$ D, Mahmood Dehghani Ashkezari², \\ Majid Pourfahraji Fakhrabadi ${ }^{1}$ and Samira Sabbagh Nejad Yazd ${ }^{1}$
}

\begin{abstract}
Background: Recurrent pregnancy loss is defined as having the experience of three or more repeated pregnancy losses. Despite numerous studies, RPL etiology remains unclear; in this respect, many etiological factors have been thoroughly investigated. However, the contribution of male factors in RPL at the sperm aneuploidy has rarely been examined. The aim of the current study is to assess the existence of autosome and sex chromosome aneuploidy in sperm of men with history of recurrent pregnancy loss. In this prospective study, 50 men with a history of recurrent pregnancy loss were included as case group and 15 men with normal sperm analysis, without abortion history and with at least one child were included as control group. Two- and three-color fluorescence in situ hybridization technique was used for screening aneuploidy in 13, 18, 21, X, and $Y$ chromosomes.

Results: Overall, the comparison of sperm aneuploidies in sex and autosome chromosomes $(13,21,18)$ between case and control groups showed that chromosomal abnormality was significantly increased in men with RPL than men without history of RPL. Among all examined cells, about $18.28 \%$ nullisomy, $6.48 \%$ disomy, and $0.06 \%$ trisomy were observed. As well, two cells with XXYY and one cell with XXXY karyotype were observed. Among the analyzed chromosomes, the prevalence of nullisomy of chromosome 13 was higher than other studied chromosomes.

Conclusion: The results suggest the implication of sperm chromosomal abnormalities in recurrent pregnancy loss. Clinical application of FISH-based screening test is recommended for investigating sperm aneuploidy in RPL cases to counsel couples for making informed decision.
\end{abstract}

Keywords: FISH, RPL, Sperm, Aneuploidy

\section{Background}

Recurrent pregnancy loss (RPL) is defined as having an experience of three or more repeated abortions [1]. It is estimated that between 0.5 and $3 \%$ of couples of reproductive age experience RPL [2]. RPL is a condition of great concern, firstly because of high prevalence, and secondly because of unknown etiology. Despite numerous studies, its cause remains unknown and the presence of a specific etiology cannot recommend a definitive

\footnotetext{
* Correspondence: marjan.montazeri@gmail.com

${ }^{1}$ Abortion Research Center, Yazd Institute of Reproductive Sciences, Shahid

Sadoughi University of Medical Sciences, Yazd, Iran

Full list of author information is available at the end of the article
}

diagnosis of cause. Six of the most important risk factors associated with RPL include genetic, endocrine, infectious, anatomical uterine defects, immunological, and idiopathic [1]. Regular gynecological examination in couples with RPL includes endocrinology, immunological, anatomical tests and blood karyotyping of both partner. On the other hand, clinical evaluation of couples with RPL is challenged by the unanswered question as "why some couples have abortions with a higher risk of chromosomal abnormalities than others" [2]. According to cytogenetic studies, aneuploidies are the most frequent chromosomal abnormalities in first-trimester miscarriages $[1,3]$. It is estimated that aneuploidies in germ 
cells are responsible for $50-80 \%$ of embryonic mortality in mammals and particularly, aneuploidies have been associated with male and female infertility and recurrent pregnancy loss [4]. Despite the important role of genetics in abortion, most couples with RPL present a normal karyotype (as 46XX and 46XY) and in most cases, the etiology remains mysterious [2]. Since the majority of aneuploidies in embryos result from meiotic nondisjunction during oogenesis and spermatogenesis in parents, somatic cell karyotyping cannot suffice [1,3]. Formerly, oocyte chromosomal constitutions have been studied well and showed a high fraction of aneuploidy caused by meiosis errors in oogenesis [1]. Though a few studies have reported high incidence of sperm aneuploidy in couples with a history of RPL [1, 5-7], the rate of chromosomal abnormalities in sperm of these men has been underestimated. Therefore, a recent line of research has been performed to investigate sperm aneuploidy frequency in couples with RPL with normal or abnormal sperm parameters together with a normal karyotype [8]. The main aim of this study is to evaluate sperm chromosomal abnormalities in couples with the history of unexplained recurrent abortion [7].

\section{Methods}

\section{Patients}

In the case/RPL group, only male partners of couples with history of RPL with normal karyotypes on peripheral blood were selected. After rejecting the endocrine (FSH, LH, TSH), immune (cardiolipins, antinuclear antibodies), and anatomical (hysterosalpiogram) causes of RPL in female partners, they were included in study. Inclusion criteria in normal group were no history of abortion in female partners, normal semen analysis in male partner and having at least one child [7]. We excluded men with known causes of infertility such as AZF microdeletions in Y-chromosome or 47; XXY karyotype, because they are infertile, naturally. According to the mentioned criteria, a total of 50 semen samples from male partners of couples with at least two previous abortions as case group and 15 semen samples from normozoospermic men as control group for comparison were included in this study. The mean age of patients and control population ranges between 25 and 55 years. Informed consent was obtained from all participants in this study.

\section{Sperm processing and analysis}

Semen samples were taken by masturbation after 2-5 days of sexual abstinence. The collected samples in each group were divided into two sections, one for semen analysis and evaluating sperm parameters and another for examining sperm aneuploidies by fluorescence in situ hybridization (FISH) technique. According to the WHO
2010 guidelines for semen analysis, motility $<40 \%$ and count $<15$ million sperm/cc and morphology $<4$ were considered abnormal [9]. For FISH technique, 1 cc fresh specimens was washed tow times in $1 \times$ phosphatebuffered saline (PBS) and once in $2 \times$ saline sodium citrate (SSC). At the end of each step, the specimens were centrifuged at room temperature at $200 \mathrm{~g}$ for $10 \mathrm{~min}$ and the supernatant was discarded. Then, the specimens were washed in $1 \mathrm{cc}$ carnoy solution (methanol/acetic acid $(3: 1)\}$. Finally, the specimens were fixed on precleaned slides and then used for next step in the FISH technique [9].

\section{FISH assay}

After slide preparation, the slides were pretreated in $2 \times$ SSC for 2 min in $37^{\circ} \mathrm{C}$. Slides were then incubated for $10 \mathrm{~min}$ at $37^{\circ} \mathrm{C}$ with pepsin solution $(0.1 \mathrm{mg}=\mathrm{ml})$ in $0.01 \mathrm{M} \mathrm{HCl}$ for enzymatic cytoplasm digestion. Each slide was immersed in a series of pre-hybridization solutions including 1× PBS for $3 \mathrm{~min}, 10 \%$ formaldehyde plus $\mathrm{MgCl} 2$ for $3 \mathrm{~min}$ and again $1 \times \mathrm{PBS}$ for $3 \mathrm{~min}$. Finally, the slides were dipped into a $70 \%, 85 \%$, and $100 \%$ ethanol series each for 1 minute and air dried. The probes were applied directly to the slides covered with a coverslip and sealed with rubber cement and then codenatured at $75{ }^{\circ} \mathrm{C}$ for $5 \mathrm{~min}$. Overnight hybridization of probes occurred in the ThermoBrithe at $37{ }^{\circ} \mathrm{C}$. After that, the slides were washed in $0.4 \times \mathrm{SSC} / 0.3 \%$ Tween 20 at $78{ }^{\circ} \mathrm{C}$ for $2 \mathrm{~min}$ and then in $2 \times \mathrm{SSC} / 0.1 \%$ Tween 20 at room temperature for $1 \mathrm{~min}$. The slides were dehydrated in ethanol series, air dried and 4,6-diamidino-2-phenylindole (DAPI) counterstain were added, last of all. Three-color FISH for chromosomes (18, X, and Y) and two-color FISH for chromosomes 13 and 21 were used to detect aneuploidies in mentioned chromosomes. FAST FISH prenatal Enumeration Probe Kit from the cytocell company (catalog no. REF LPF001-30) was used. The slides were analyzed using an Olympus fluorescence microscope BX61 (C Zeiss, Oberkochen, Germany) with the appropriate set of filters including single band DAPI, FITC, Texas Red, and Aqua. Each nucleus was to be scored by two analysts according a general guideline for scoring a single signal. Also, Applied Spectral Imaging (ASI) software was used to capture an image of the nucleus and signals related to applied probes $[8,10]$.

\section{Statistical analysis}

The data were categorized and presented in frequencies and percentages, when more than $25 \%$ of table cells having a frequency of less than $5 \%$. Chi-square test was used for statistical analysis. In tables which data frequency has a smaller amount, Fisher exact test with less power was used. Comparisons of frequency data between groups, such as fertilization and developmental rates, 
were performed using chi-square tests by the SPSS software (Statistical Package for the Social Sciences version 20.0, SPSS Inc., Chicago, IL, USA). $p$ value $<0.05$ was considered as statistical significance.

\section{Result}

As shown in Table 1, the average abortion rate for men who entered the study is $3 \pm 1.161$. Average male age was 36.73 and 34.26 years in control and case group, respectively. Although the sperm motility of the RPL men did not show any significant difference compared to the control group, the count and morphology of sperm were significantly different between the two groups $(p<0.05)$. Aneuploidy screening include haploid, nullisomy, disomy, and trisomy for RPL patients $(n=50)$ and control group $(n=15)$ are shown in Table 2. Efficiency of denaturation and hybridization were in all cases higher than $99 \%$. Totally, 2500 spermatozoa were screened for chromosomes 13, 18, 21, X, and Y in each group. Aneuploidy in these chromosomes was screened because they are prevalent, also able to reach the term. In control group (Table 2$)$, totally 132 cells $(5.2 \%)$ were abnormal, including 106 nullisomy and 26 disomy. Abnormalities were detected in $(41 \%)$ of analyzed cells in RPL men with normal semen and (50.6\%) of cells in RPL men with abnormal semen. Total chromosome aneuploidy was significantly increased $(P<0.0001)$ in men with RPL compared to those in control group. However, aneuploidy rates were not increased significantly in RPL men with abnormal semen compared to RPL men with normal semen with the exception of aneuploidy in chromosomes 21 (Fig. 1). Among all examined cells, about $18.28 \%$ nullisomy, $6.48 \%$ disomy, and $0.06 \%$ trisomy were observed. Furthermore, two cells with XXYY and one cell with XXXY karyotype were observed (Table 2). Moreover, the findings showed that the highest prevalence abnormality belongs to chromosome 21 , also that nullisomy is the most common type of aneuploidy in sperm. In Fig. 2, a number of FISH results are shown. Investigating the effect of age on the rate of chromosomal abnormalities showed that the most of the aneuploidies in both group were observed in the age group of

Table 1 Baseline characteristics of men with recurrent pregnancy loss (RPL) and normal men

\begin{tabular}{llll}
\hline & $\begin{array}{l}\text { Men whit RPL } \\
(n=50)\end{array}$ & $\begin{array}{l}\text { Control } \\
(n=15)\end{array}$ & $p$ value \\
\hline Age & $34.26 \pm 5.252$ & $36.73 \pm 5.45$ & 0.11 \\
Average of RPL & $3 \pm 1.161$ & 0 & 0.0001 \\
Semen analysis & & & \\
Morph & $4.66 \pm 2.134$ & $6.26 \pm 2.18$ & 0.016 \\
Motility & $42.36 \pm 11.21$ & $43.80 \pm 8.45$ & 0.077 \\
Count & $85.70 \pm 39.18$ & $110.98 \pm 40.34$ & 0.016 \\
\hline
\end{tabular}

35-39 years. Maximum aneuploidies in the age group of $35-39$ years were $31.851 \%$ and $53.65 \%$ in RPL men and normospermic men, respectively (Table 3 ).

\section{Discussion}

Today, considering the significance of IVF or intra cytoplasmic sperm injection (ICSI) in male infertility treatment, access to normal sperm for micro-manipulation and investigating causes of failure has become more important [11]. Standard clinical investigations of the male partner of couples with a history of RPL have involved only semen analysis and most practical clinical genetic testing is currently limited to peripheral blood karyotyping and Y-chromosome microdeletion analysis $[7,9,11$, 12]. However, direct sperm nucleus analysis considering chromosomal abnormalities has not yet been carried out. Chromosome abnormalities could occur de novo in the germ cell line during spermatogenesis [13]. Therefore, a normal blood karyotype is not representative of sperm chromosomal makeup. Previous meiotic studies revealed that part of chromosomal abnormalities in testicular biopsies could occur during meiotic nondisjunction [14] or because of an abnormal testicular environment $[7,15]$ during spermatogenesis $[1,16]$. Hence, sperm aneuploidy screening of RPL male partner is of great interest to judge about their chromosomal constitution.

Routine sperm analysis is more based on morphologic criteria rather than identifying genetic abnormalities such as aneuploidy. Previous studies have shown increasing rate of sperm aneuploidy in men with spermatogenic impairment [17-19], men with infertility [20, 21 ] and in couples with a history of RPL. Unfortunately, men with normal semen analysis and RPL/IVF failure are not usually counseled and recommended to do supplemented genetic tests. It is important to note that the frequency of aneuploidy may be high, even in men with normal semen analysis $[9,22]$. Our findings showed significant difference between normal morphology and the rate of chromosomal aneuploidies in sperm. Hence, more than $50 \%$ of all sperm with normal morphology showed aneuploidies in one of investigated chromosomes (Table 4).

Direct evaluation of chromosomal abnormalities in sperm of couples with RPL has been performed by multicolor FISH technique. According to our findings, $41 \%$ of normospermic men in RPL group showed abnormalities in the examined chromosomes. Former study of sperm chromosomal constitution of zona-free hamster egg by karyotyping did not demonstrate any difference for sperm aneuploidies between RPL and control [23]. However, recently, few studies have revealed a considerable increase in aneuploidies in sperm of couples with RPL or abortion following the IVF/ICSI procedure $[1,5$, 
Table 2 Frequency of aneuploidy in men with RPL and normospermic men according to each chromosome and aneuploidy type

\begin{tabular}{|c|c|c|c|c|c|}
\hline \multicolumn{3}{|l|}{ Sperm FISH results } & \multirow{3}{*}{$\begin{array}{l}\text { Control } \\
\text { Normal semen }\end{array}$} & \multirow{3}{*}{$N(\%)$} & \multirow{3}{*}{$\frac{p \text { value }}{\mathbf{0 . 0 0 0 1}}$} \\
\hline & Men with RPL & & & & \\
\hline & With normal semen & With abnormal semen & & & \\
\hline No. of analyzed sperm & $1600(100 \%)$ & $900(100 \%)$ & 2500 & $5000(100 \%)$ & \\
\hline Number of haploid & $944(59 \%)$ & 444 (49.33) & 2368 (94.72\%) & $3756(75.12 \%)$ & \\
\hline Nullisomy & $460(28.75 \%)$ & $348(38.66 \%)$ & 106 (4.24\%) & 914(18.28\%) & 0.0001 \\
\hline 13 & $194(12.125 \%)$ & 118(13.11\%) & $51(2.04 \%)$ & & \\
\hline 18 & $92(5.75 \%)$ & $61(6.77 \%)$ & $6(0.24 \%)$ & & \\
\hline 21 & $85(5.312 \%)$ & 115(12.77\%) & $37(1.48 \%)$ & & \\
\hline Sex & $89(5.562 \%)$ & $54(6 \%)$ & $12(0.48 \%)$ & & \\
\hline Disomy & $194(12.125 \%)$ & $104(11.55 \%)$ & $26(1.04 \%)$ & $324(6.48 \%)$ & 0.0001 \\
\hline 13 & $51(3.187 \%)$ & $24(2.66 \%)$ & $8(0.32 \%)$ & & \\
\hline 18 & $16(1 \%)$ & $12(1.33 \%)$ & $6(0.24 \%)$ & & \\
\hline 21 & $66(4.125 \%)$ & $23(2.55 \%)$ & $4(0.16 \%)$ & & \\
\hline Sex & $61(3.812 \%)$ & $45(5 \%)$ & $8(0.32 \%)$ & & \\
\hline Trisomy & 0 & $3(0.33 \%)$ & 0 & $3(0.06 \%)$ & 0.0001 \\
\hline 13 & 0 & $1(0.11 \%)$ & 0 & & \\
\hline 18 & 0 & $1(0.11 \%)$ & 0 & & \\
\hline 21 & 0 & $1(0.11 \%)$ & 0 & & \\
\hline Others & $2(0.125 \%)$ & $1(0.11 \%)$ & 0 & $3(0.06 \%)$ & \\
\hline Total abnormal & 656 (41\%) & 456 (50.67\%) & 132 (5.28\%) & & \\
\hline
\end{tabular}

24]. Unfortunately, these countless studies and our work have investigated a limited number of chromosomes, i.e., $13,18,21, \mathrm{X}$, and $\mathrm{Y}$. A more comprehensive genetic investigation of sperm may reveal more abnormalities affecting the incidence of RPL. Previous studies have found that chromosomal breaks and acentric fragments are significantly higher in RPL patients [23]. An animal study has demonstrated paternally transmitted chromosomal abnormalities in mouse zygote to be associated with embryonic loss [25]. Two other studies have shown that transmission of chromosomal abnormalities from sperm results in sex chromosome nullisomy in one case and aneuploidy of chromosome 15 in another case, respectively in offspring $[7,26,27]$.

Considering the fact that we observed increase of aneuploidy in both autosomal and sex chromosomes, it is

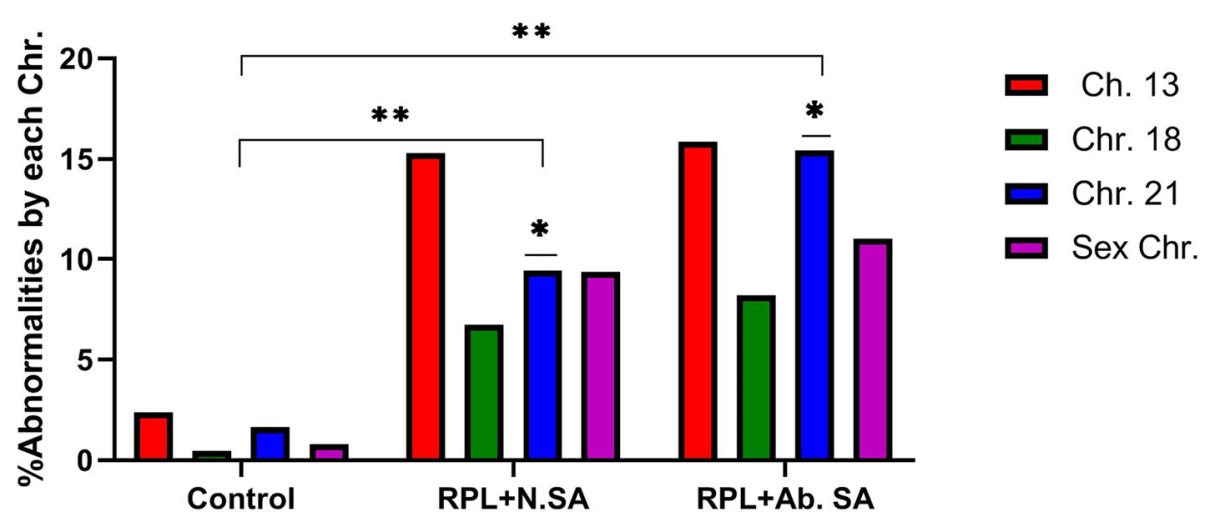

Fig. 1 Comparison of aneuploidy by each chromosome in men with RPL normal SA, abnormal SA, and normospermic men. *Significant difference between RPL men with normal and abnormal semen was shown just according aneuploidy in chromosome 21 ( $p<0.05)$. ${ }^{* * B u t}$ aneuploidies in all investigated chromosomes were significantly different between two RPL groups comparing to control group ( $p<0.0001)$. RPL: recurrent pregnancy loss; N.SA: normal semen analysis; Ab.SA: abnormal semen analysis; Chr: chromosome 


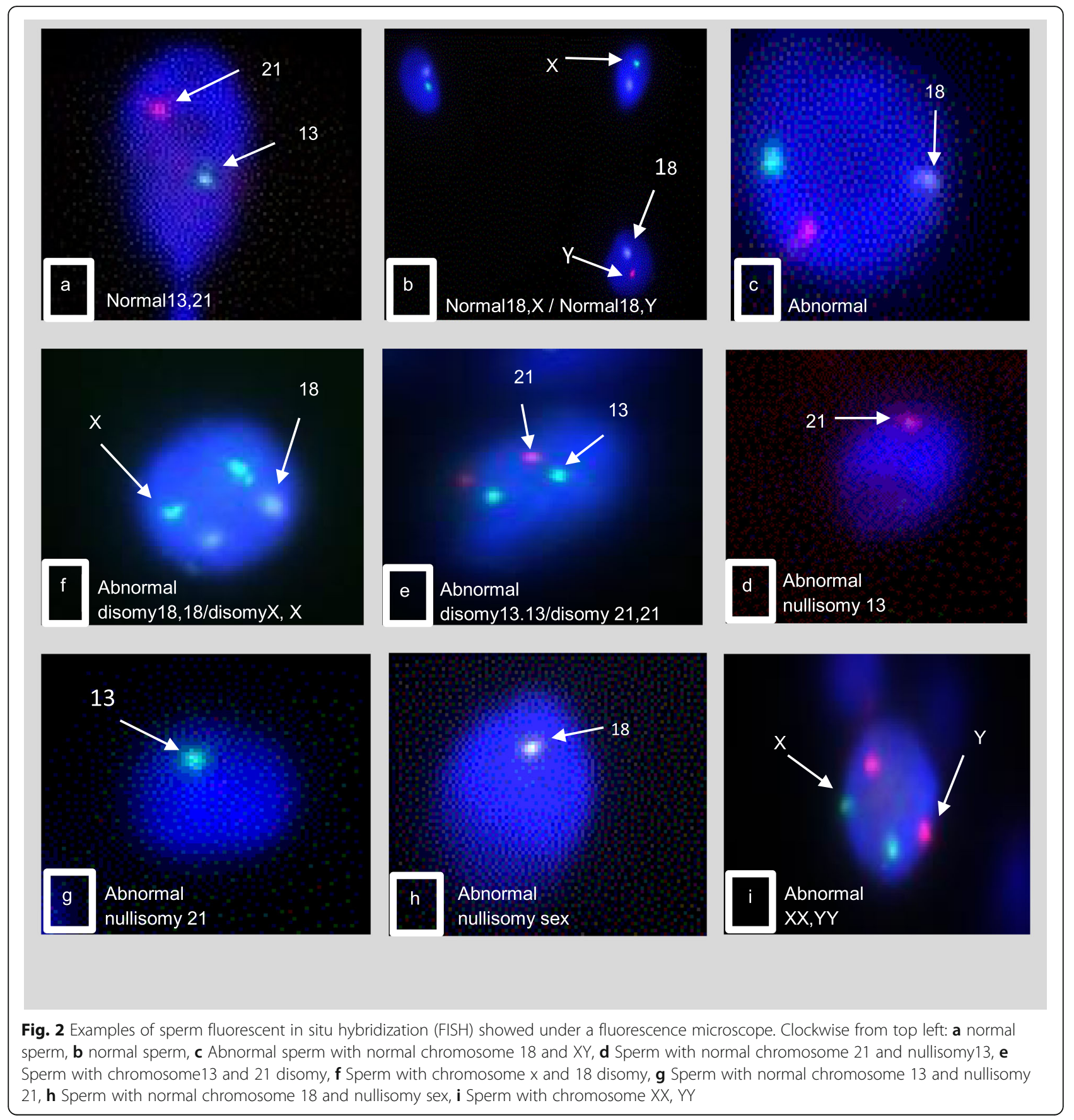

predicted that the meiotic recombination errors in sperm would involve equally and randomly all chromosomes. Therefore, in the sperm of men with Klinefelter syndrome, increase in disomy of chromosome 21 has been reported. It is known that a significant increase in disomy and nullisomy of $13,18,21$, and XY chromosomes in spermatozoa will lead to trisomic and monosomic offspring $[9,28]$.

Our findings, along with similar results, support the role of sperm aneuploidy and generally, genetic etiology of sperm in the RPL. However, the existence of toxic factors for sperm and spermatogenesis, also maternal contribution, should not be completely ignored [29]. FISH-based diagnosis is the technique of choice for analysis of limited number of chromosome including common chromosomal abnormalities of sperms in order to improve the efficiency of in vitro fertilization (IVF), also in the management of couples with RPL [29]. Detection of specific chromosomal abnormalities in sperm would help to make informed reproductive choices. Couples 
Table 3 The effect of paternal age on frequency of chromosomal aneuploidy in sperm

\begin{tabular}{llll}
\hline & Age & Number of analyzed sperms & \% chromosomal aneuploidy \\
\hline RPL group & $25-29$ & 500 & $23.097 \%$ \\
& $30-34$ & 750 & $30.303 \%$ \\
& $35-39$ & 850 & $\mathbf{3 1 . 8 5 1 \%}$ \\
& $40 \leq$ & 400 & $14.747 \%$ \\
Control group & 2500 & $100 \%(1112)$ & $0 \%$ \\
& Total & 165 & $17.07 \%$ \\
& $30-34$ & 665 & $\mathbf{5 3 . 6 5 \%}$ \\
& $35-39$ & 835 & $29.26 \%$ \\
& $40 \leq$ & 2500 & $100 \%(132)$ \\
\hline
\end{tabular}

with history of RPL and repeated IVF failure (RIF) should be counseled concerning treatment and diagnostic strategies, such as using sperm donation or preimplantation genetic screening/diagnosis to help the transfer of normal embryo and consequently decrease abortions [30, 31].

\section{Conclusions}

Since the introduction of FISH technique, it has been commonly integrated into the diagnosis, screening, and treatment of the infertility and RPL/RIF. Although sperm FISH tests is available and relatively simple, multicolor FISH requires experience and skill to increase its facility and validity. Clinical application of FISHbased tests may be decreased due to weaknesses such as high cost, technician timing, and the limited number of chromosomes studied in each round.

However, FISH can detect the rate of aneuploidy in different samples including ejaculated, epididymal, and testicular sperm for diagnostic purposes in male infertility. Clinically, results from this screening tool can be used in genetic counseling of couples suffering from

Table 4 Comparison of FISH result in men with normal and abnormal strict morphology

\begin{tabular}{|c|c|c|c|}
\hline \multicolumn{2}{|l|}{ Semen analysis } & \multirow{2}{*}{$\begin{array}{l}\text { Normal } \\
\text { morphology } \\
(\%)\end{array}$} & \multirow{2}{*}{$\begin{array}{l}\text { Abnormal } \\
\text { morphology } \\
(\%)\end{array}$} \\
\hline FISH result & & & \\
\hline \multirow[t]{2}{*}{ Chromosom13 } & Normal & 86 & 14 \\
\hline & Abnormal & 75.4 & 24.6 \\
\hline \multirow[t]{2}{*}{ Chromosom18 } & Normal & 86.3 & 13.7 \\
\hline & Abnormal & 65.9 & 34.1 \\
\hline \multirow[t]{2}{*}{ Chromosom21 } & Normal & 85.4 & 14.6 \\
\hline & Abnormal & 74.5 & 25.5 \\
\hline \multirow[t]{2}{*}{ Chromosome sex } & Normal & 85.8 & 14.2 \\
\hline & Abnormal & 70.4 & 29.6 \\
\hline
\end{tabular}

male factor infertility and RPL/RIF to make informed decision concerning their ART cycles.

\section{Abbreviations}

RPL: Recurrent pregnancy loss; FISH: Fluorescence in situ hybridization; IVF: In vitro fertilization; ICSI: Intracytoplasmic sperm injection; RIF: Repeated IVF failure

\section{Acknowledgements}

This research has been done in the andrology and abortion Center of Institute of Reproductive Sciences of Shahid Sadoughi University of Medical Sciences.

The authors would like to express their gratitude to all the clinical staff in the andrology and abortion center who participated in this trial.

\section{Authors' contributions}

MPF contributed mainly in the data collection, practical part, analysis of results, and drafting of the manuscript. SMK contributed in the study design, supervision of the practical part, revising and data interpretation. FM participated in writing up the paper, revising and analysis of results. MDA contributed to the final revision. MPF contributed in the data collection, analysis of results, and drafting of the manuscript. SSNY contributed to practical part. All authors have read and approved the final manuscript.

\section{Funding}

No funding was obtained for this study.

\section{Availability of data and materials}

The data will not be shared because it is the policy of our center.

\section{Ethics approval and consent to participate}

The study was ethically approved by Institute of Reproductive Sciences of Shahid Sadoughi University of Medical Sciences ethical approval committee (ethic number, IR.SSU.RSI.REC.1396.20). All participants had signed a written informed consent (in Persian), and all consents are saved with patients' data in this institute.

\section{Consent for publication}

All authors agreed for the publication at MEF journal.

\section{Competing interests}

The authors declare that they have no competing interests.

\section{Author details}

${ }^{1}$ Abortion Research Center, Yazd Institute of Reproductive Sciences, Shahid Sadoughi University of Medical Sciences, Yazd, Iran. ${ }^{2}$ Medical Biotechnology Research Center, Ashkezar Branch, Islamic Azad University, Ashkezar, Yazd, Iran. ${ }^{3}$ Yazd Institute of Reproductive Sciences, Shahid Sadoughi University of Medical Sciences, Yazd, Iran. 
Received: 4 October 2019 Accepted: 11 June 2020

Published online: 01 July 2020

\section{References}

1. Rubio C, Simon C, Blanco J, Vidal F, Minguez Y, Egozcue J et al (1999) Implications of sperm chromosome abnormalities in recurrent miscarriage. J Assist Reprod Genet 16(5):253-258

2. Bernardini LM, Costa M, Bottazzi C, Gianaroli L, Magli MC, Venturini PL et al (2004) Sperm aneuploidy and recurrent pregnancy loss. Reprod BioMed Online 9(3):312-320

3. Sarrate Z, Vidal F, Blanco J (2010) Role of sperm fluorescent in situ hybridization studies in infertile patients: indications, study approach, and clinical relevance. Fertil Steril 93(6):1892-1902. https://doi.org/10.1016/j. fertnstert.2008.12.139

4. Pauciullo A, Cosenza G, Peretti V, lannuzzi A, Di Meo GP, Ramunno L et al (2011) Incidence of X-Y aneuploidy in sperm of two indigenous cattle breeds by using dual color fluorescent in situ hybridization (FISH). Theriogenology 76(2):328-333. https://doi.org/10.1016/j.theriogenology. 2011.02.010

5. Carrell DT, Wilcox AL, Lowy L, Peterson CM, Jones KP, Erickson L et al (2003) Elevated sperm chromosome aneuploidy and apoptosis in patients with unexplained recurrent pregnancy loss. Obstet Gynecol 101(6):1229-1235

6. Giorlandino C, Calugi G, laconianni L, Santoro ML, Lippa A (1998) Spermatozoa with chromosomal abnormalities may result in a higher rate of recurrent abortion. Fertil Steril 70(3):576-577

7. Al-Hassan S, Hellani A, Al-Shahrani A, Al-Deery M, Jaroudi K, Coskun S (2005) Sperm chromosomal abnormalities in patients with unexplained recurrent abortions. Arch Androl 51(1):69-76. https://doi.org/10.1080/ 014850190518062

8. Calogero AE, Burrello N, De Palma A, Barone N, D'Agata R, Vicari E (2003) Sperm aneuploidy in infertile men. Reprod BioMed Online 6(3):310-317

9. Ramasamy R, Scovell JM, Kovac JR, Cook PJ, Lamb DJ, Lipshultz LI (2015) Fluorescence in situ hybridization detects increased sperm aneuploidy in men with recurrent pregnancy loss. Fertil Steril 103(4):906-909e901. https:// doi.org/10.1016/j.fertnstert.2015.01.029

10. Montazeri F, Foroughmand AM, Kalantar SM, Aflatoonian A, Khalilli MA (2018) Tips and tricks in fluorescence in-situ hybridization (FISH)- based preimplantation genetic diagnosis/screening (PGD/PGS). International Journal of Medical Laboratory 5(2):84-98

11. Hotaling J, Carrell DT (2014) Clinical genetic testing for male factor infertility: current applications and future directions. Andrology 2(3):339-350. https:// doi.org/10.1111/j.2047-2927.2014.00200.x

12. Carp H, Feldman B, Oelsner G, Schiff E (2004) Parental karyotype and subsequent live births in recurrent miscarriage. Fertil Steril 81(5):1296-1301. https://doi.org/10.1016/j.fertnstert.2003.09.059

13. Kurahashi $\mathrm{H}$, Emanuel BS (2001) Unexpectedly high rate of de novo constitutional $\mathrm{t}(11 ; 22)$ translocations in sperm from normal males. Nat Genet 29(2):139-140. https://doi.org/10.1038/ng1001-139

14. Barlow AL, Hulten MA (1996) Combined immunocytogenetic and molecular cytogenetic analysis of meiosis I human spermatocytes. Chromosom Res 4(8):562-573

15. Mroz K, Hassold TJ, Hunt PA (1999) Meiotic aneuploidy in the XXY mouse: evidence that a compromised testicular environment increases the incidence of meiotic errors. Hum Reprod 14(5):1151-1156

16. Egozcue J, Templado C, Vidal F, Navarro J, Morer-Fargas F, Marina S (1983) Meiotic studies in a series of 1100 infertile and sterile males. Hum Genet 65(2):185-188

17. Retief AE, Van Zyl JA, Menkveld R, Fox MF, Kotze GM, Brusnicky J (1984) Chromosome studies in 496 infertile males with a sperm count below 10 million/ml. Hum Genet 66(2-3):162-164

18. Matsuda T, Horii Y, Ogura K, Nonomura M, Okada K, Yoshida O (1992) Chromosomal survey of 1001 subfertile males: incidence and clinical features of males with chromosomal anomalies. Hinyokika Kiyo 38(7):803809

19. Rucker GB, Mielnik A, King P, Goldstein M, Schlegel PN (1998) Preoperative screening for genetic abnormalities in men with nonobstructive azoospermia before testicular sperm extraction. J Urol 160(6 Pt 1):20682071

20. Wong EC, Ferguson KA, Chow V, Ma S (2008) Sperm aneuploidy and meiotic sex chromosome configurations in an infertile XYY male. Hum Reprod 23(2):374-378. https://doi.org/10.1093/humrep/dem377
21. Ferguson KA, Wong EC, Chow V, Nigro M, Ma S (2007) Abnormal meiotic recombination in infertile men and its association with sperm aneuploidy. Hum Mol Genet 16(23):2870-2879. https://doi.org/10.1093/hmg/ddm246

22. Ryu HM, Lin WW, Lamb DJ, Chuang W, Lipshultz LI, Bischoff FZ (2001) Increased chromosome $X, Y$, and 18 nondisjunction in sperm from infertile patients that were identified as normal by strict morphology: implication for intracytoplasmic sperm injection. Fertil Steril 76(5):879-883

23. Rosenbusch B, Sterzik K (1991) Sperm chromosomes and habitual abortion. Fertil Steril 56(2):370-372

24. Lathi RB, Milki AA (2004) Rate of aneuploidy in miscarriages following in vitro fertilization and intracytoplasmic sperm injection. Fertil Steril 81(5): 1270-1272. https://doi.org/10.1016/j.fertnstert.2003.09.065

25. Marchetti F, Bishop JB, Cosentino L, Moore D 2nd, Wyrobek AJ (2004) Paternally transmitted chromosomal aberrations in mouse zygotes determine their embryonic fate. Biol Reprod 70(3):616-624. https://doi.org/ 10.1095/biolreprod.103.023044

26. Carrell DT, Wilcox AL, Udoff LC, Thorp C, Campbell B (2001) Chromosome 15 aneuploidy in the sperm and conceptus of a sibling with variable familial expression of round-headed sperm syndrome. Fertil Steril 76(6):1258-1260

27. Tang SS, Gao H, Robinson WP, Ho Yuen B, Ma S (2004) An association between sex chromosomal aneuploidy in sperm and an abortus with 45,X of paternal origin: possible transmission of chromosomal abnormalities through ICSI. Hum Reprod 19(1):147-151

28. Vialard F, Bailly M, Bouazzi H, Albert M, Pont JC, Mendes V et al (2012) The high frequency of sperm aneuploidy in klinefelter patients and in nonobstructive azoospermia is due to meiotic errors in euploid spermatocytes. J Androl 33(6):1352-1359. https://doi.org/10.2164/jandrol. 111.016329

29. Egozcue J, Blanco J, Vidal F (1997) Chromosome studies in human sperm nuclei using fluorescence in-situ hybridization (FISH). Hum Reprod Update 3(5):441-452

30. Vidal F, Gimenez C, Rubio C, Simon C, Pellicer A, Santalo J et al (1998) FISH preimplantation diagnosis of chromosome aneuploidy in recurrent pregnancy wastage. J Assist Reprod Genet 15(5):310-313

31. Simon C, Rubio C, Vidal F, Gimenez C, Moreno C, Parrilla JJ et al (1998) Increased chromosome abnormalities in human preimplantation embryos after in-vitro fertilization in patients with recurrent miscarriage. Reprod Fertil Dev 10(1):87-92

\section{Publisher's Note}

Springer Nature remains neutral with regard to jurisdictional claims in published maps and institutional affiliations.

\section{Submit your manuscript to a SpringerOpen ${ }^{\circ}$ journal and benefit from:}

- Convenient online submission

- Rigorous peer review

- Open access: articles freely available online

High visibility within the field

- Retaining the copyright to your article

Submit your next manuscript at $>$ springeropen.com 